interesting relationship indicated in Fig. 3. Fig. 3(a) is a section through the equatorial plane containing $\mathrm{Fe}$, $\mathrm{N}(18)$ and $\mathrm{O}(11)$, which also passes close to $\mathrm{N}(28)$ and $\mathrm{O}(21)$. Figs. $3(b)$ and $3(c)$ are sections parallel to Fig. $3(a)$, but $0.3 \AA$ closer to the imidazole groups containing $\mathrm{N}(31)$ and $\mathrm{N}(41)$ respectively. It is clear from Fig. $3(b)$ that two of the tetrahedral maxima around the Fe atom are close to the plane containing the $N(31)$ imidazole group, even though one of the maxima does not reach full height in the section shown. Both maxima are close to vectors linking the central $\mathrm{Fe}$ atom to imidazole $\mathrm{H}$ atoms.

As seen in Fig. 3(c), the deformation density is not symmetry related to the imidazole group containing $\mathrm{N}(41)$. To bring that subsystem into conformity with the arrangement in Fig. $3(b)$ would require rotation of the $N(41)$ imidazole group by approximately $50^{\circ}$ about the $\mathrm{N}(31) \cdots \mathrm{N}(41)$ vector. At that stage it would be at right angles to the $\mathrm{N}(31)$ imidazole group. In its actual configuration without that rotation, the $\mathrm{N}(41)$ imidazole has the configuration characteristic of the high-spin form of the cation, as identified in $\left[\mathrm{Fe}(\mathrm{salen})(\mathrm{imd})_{2}\right] \mathrm{PF}_{6}$ by Kennedy, McGrath, Murray, Skelton \& White (1987).

We postulate that in the ideal low-spin structure the imidazole rings are at right angles to each other, and coincident with the planes bisecting the $\mathrm{O}(11)-\mathrm{Fe}-$ $\mathrm{N}(18)$ and the $\mathrm{N}(18)-\mathrm{Fe}-\mathrm{N}(28)$ angles respectively. The vectors from the $\mathrm{Fe}$ to the four imidazole $\mathrm{H}$ atoms would then describe a tetrahedron similar to that defined by the lobes of excess density in the spin crossover complex shown in Fig. 3. However, only one imidazole group is actually in the configuration which favours low spin. The other is oriented so as to favour high spin, which is the reason for the instability in this structure. It is clear from packing diagrams (not shown) that the imidazole groups are held in this mixed configuration by solvent molecules - accounting for their effect on the spin transition. This explains the indirect nature of their role in the magnetic properties of the structures containing these complexes noted by Kennedy, McGrath, Murray, Skelton \& White (1987).

Thanks are due to A. H. White, who suggested the problem, for supervising the data collection. This work was supported by the Australian Research Grants Scheme.

\section{References}

Davis, C. L. \& Maslen, E. N. (1978). Acta Cryst. A34, 743-746. International Tables for X-ray Crystallography (1774). Vol. IV. Birmingham: Kynoch Press. (Present distributor D. Re'del, Dordrecht.)

HirshFeld, F. L. (1977). Theor. Chim. Acta, 44, 129-138.

JoHNSON, C. K. (1965). ORTEP. Report ORNL-3794. Oak Rı !ge National Laboratory, Tennessee, USA.

Kennedy, B. J., McGrath, A. C., Murray, K. S., Skelton, B. S. \& WhITE, A. H. (1987). Inorg. Chem. 26, 483-495.

Maslen, E. N. \& Ridout, S. C. (1987). Acta Cryst. B43, 352-356.

Maslen, E. N., Ridout, S. C. \& Watson, K. J. (1988). Acta Cryst. B44, 96-101.

Stewart, J. M. \& HALL, S. R. (1983). XTAL User's Manual. Computer Science Center, Univ. of Maryland, College Park, Maryland, USA.

Stewart, R. F., Davidson, E. R. \& Simpson, W. T. (1965). J. Chem. Phys. 42, 3175-3187.

Acta Cryst. (1988). B44, 259-262

\title{
Lattice-Energy Calculations on Organometallic Compounds
}

\author{
By J. SAnz-A Paricio, S. Martínez-Carrera and S. García-Blanco \\ UEI de Cristalografia, Instituto 'Rocasolano', CSIC, Serrano 119, 28006 Madrid, Spain
}

\begin{abstract}
AND A. CONDE
Departamento de Fisica del Estado Sólido, Instituto de CC de los Materiales de Sevilla, Universidad de Sevilla, CSIC, 41080 Sevilla, Spain
\end{abstract}

(Received 5 October 1987; accepted 21 January 1988)

\begin{abstract}
Lattice-energy calculations in the atom-atom approach have been performed for five organometallic compounds of previously determined crystal structure. Minimization of energy in terms of positional, orientational, torsional and cell parameters gave satisfactory results. Computation of energy as a function of torsion angle gave two-dimensional cross sections which
\end{abstract}

0108-7681/88/030259-04\$03.00 present minimum-energy conformations at maximum deviations of $10^{\circ}$ from the experimental conformations.

\section{Introduction}

Packing analysis following the atom-atom approach (Kitaigorodsky, 1973) has been used in determining the crystal structure of a large variety of organic com(c) 1988 International Union of Crystallography 
Table 1. Non-bonded potential function coefficients

For mixed interactions, the geometric rule for attractive and repulsive terms separately is:

\begin{tabular}{cccc}
\multicolumn{4}{c}{$A_{a b}=\left(A_{a} A_{b}\right)^{1 / 2}, B_{a b}=\left(B_{a} B_{b}\right)^{1 / 2}, C_{a b}=\left(C_{a}+C_{b}\right) / 2}$. \\
Interaction & $A\left(\mathrm{~kJ}^{6}\right)$ & $B(\mathrm{~kJ})$ & $C\left(\AA^{-1}\right)$ \\
Ta-Ta & $27713 \cdot 1$ & 728721 & 2.92 \\
$\mathrm{Nb}-\mathrm{Nb}$ & $27713 \cdot 1$ & 728721 & 2.92 \\
$\mathrm{Fe}-\mathrm{Fe}$ & 11437.3 & 275299 & 3.03 \\
$\mathrm{Cl}-\mathrm{Cl}$ & 5977.4 & 922944 & 3.62 \\
$\mathrm{~S}-\mathrm{S}$ & 4552.0 & 216386 & 3.30 \\
P-P & 5982.9 & 923602 & 3.62 \\
Si-Si & 5982.9 & 923602 & 3.62 \\
O-O & 836.0 & 779152 & 4.55 \\
N-N & 3176.8 & 4405572 & 3.60 \\
C-C & 1759.8 & 299288 & 3.68 \\
H-H & 121.2 & 20482 & 4.29
\end{tabular}

pounds, including molecules containing atoms other than $\mathrm{C}, \mathrm{H}$ or $\mathrm{O}$ (Villares, Jiménez-Garay, Conde \& Márquez, 1976; Estrada, Conde \& Márquez, 1983).

Minimization of energy in terms of the torsional angles is currently being performed in conformational analysis with the aim of elucidating structure-activity relationships in compounds possessing some chain flexibility.

In the present paper, the validity of the atom-atom model for the potential energy of interaction between molecules of organometallic compounds is investigated. For this purpose, five compounds, whose structures have been previously solved, were chosen: (I), $\quad\left[\mathrm{Fe}\left(\eta^{5}-\mathrm{C}_{5} \mathrm{H}_{5}\right)\left\{\mathrm{SP}(=\mathrm{S})\left(\mathrm{OPr}_{2}\right)_{2}\right\}(\mathrm{CO})_{2}\right] \quad$ (SanzAparicio, Martinez-Carrera \& Garcia-Blanco, 1986a); (II), $\quad\left[\mathrm{Fe}\left(\eta^{5}-\mathrm{C}_{5} \mathrm{Me}_{5}\right)\left\{\mathrm{SP}(=\mathrm{S})\left(\mathrm{OPr}^{\mathrm{i}}\right)_{2}\right\}(\mathrm{CO})_{2}\right] \quad(\mathrm{Sanz}-$ Aparicio, Martínez-Carrera \& García-Blanco, 1986b); (III) $\quad\left[\mathrm{Fe}\left(\eta^{5}-\mathrm{C}_{5} \mathrm{H}_{5}\right)\left\{\mathrm{SP}(=\mathrm{S})(\mathrm{OEt})_{2}\right\}(\mathrm{CO})_{2}\right] \quad$ (SanzAparicio, Martínez-Carrera \& García-Blanco, 1987); (IV), $\quad\left[\mathrm{Nb}\left\{\mathrm{N}\left(\mathrm{SiMe}_{3}\right)_{2}\right\}\left(\mathrm{NSiMe}_{3}\right)\left(\mu-\mathrm{OCH}_{3}\right) \mathrm{Cl}\right] \quad$ (Antiñolo, Otero, Urbanos, Garcia-Blanco, MartínezCarrera \& Sanz-Aparicio, 1988); (V), [Ta $\left(\eta^{5}-\mathrm{C}_{5} \mathrm{Me}_{5}\right)$ $\left.\left\{\mathrm{CH}_{2} \mathrm{P}(\mathrm{Ph})_{2} \mathrm{Me}\right\} \mathrm{Cl}_{4}\right]$ (Fandos, Gómez, Royo, GarcíaBlanco, Martínez-Carrera \& Sanz-Aparicio, 1987).

The theoretical equilibrium structure of all of these compounds was determined by lattice-energy minimization, the energy being calculated within the atom-atom approach. Comparisons between experimental and calculated structures were used to assess the reliability of the method.

The shape of the crystal energy surface in the surroundings of the minimum was also studied, by carrying out lattice-energy calculations as a function of torsional angle.

\section{Description of the calculations}

Lattice-energy calculations were performed using the computer program PCK6 (Williams, 1972), in which the lattice energy of a crystal is approximated by a pairwise sum over non-bonded interatomic potential functions of atoms in different molecules, following the Buckingham form $U(r)=-A r^{-6}+B \exp (-C r)$; a distance of $6 \AA$ was set as the summation limit. The variables considered in the calculations were six rigid-body degrees of freedom and the parameters of the unit cell. Some molecular flexibility was allowed in the form of internal rotations about bonds (subrotations), and intramolecular contacts were evaluated using subrotation potentials of the $\cos ^{2} \alpha$ type, to allow for conjugation energy. The rotations considered within each compound are shown below.

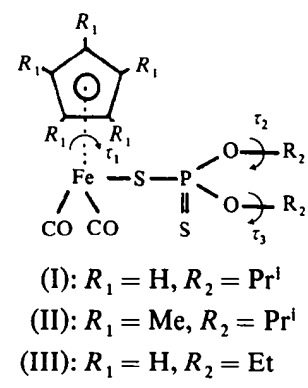

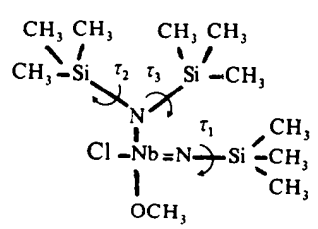

(IV)

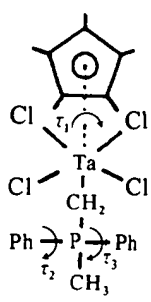

(V)

Starting from the experimental crystal structure, the structural parameters were optimized to give a theoretical equilibrium structure for checking against the experimental one. For the potential functions corresponding to $\mathrm{Ta}, \mathrm{Nb}, \mathrm{Fe}, \mathrm{Si}$ and $\mathrm{P}$ atoms, parameters determined by Mason \& Rice (1954a) for the corresponding noble gases were used with the assumption that the van der Waals radii are similar. Energy values obtained in this way are meaningless in an absolute sense and they are not given. For the $\mathrm{Cl} \cdots \mathrm{Cl}$ interactions, parameters were taken from Mason \& Kreevoy (1955) and for S...S interactions, from Rinaldi \& Pawley (1973). For $\mathrm{O}$ and $\mathrm{N}$ atoms, coefficients fitted by Giglio, Liquori \& Mazzarella (1969) and Govers (1975) respectively were applied. Finally, $\mathrm{C} \cdots \mathrm{C}$ and $\mathrm{H} \cdots \mathrm{H}$ interactions were evaluated by Mirsky (1976) potential functions. For mixed interactions, the geometric mean rule for separate attractive and repulsive terms (Mason \& Rice, 1954b) was used. This rule leads to the following expressions: $A_{a b}=\left(A_{a} A_{b}\right)^{1 / 2}, B_{a b}=\left(B_{a} B_{b}\right)^{1 / 2}$ and $C_{a b}=\left(C_{a}+C_{b}\right) / 2$. All the independent parameters are listed in Table 1.

It is generally accepted that the electrostatic energy has a small influence on the molecular position of crystals, because it is a rather slowly varying function 
of the structure parameters. This assertion was tested in our organometallic compounds by considering Coulombic energy. The effective charge on each atom was evaluated empirically by means of an expression (Skorczyk, 1976) which takes account of the percentage ionic character, depending on the difference in electronegativity between bonded atoms. All the atoms were considered to be in an oxidation state of 0 .

Since $\mathrm{H}$ atoms are critical in determining molecular interactions, they were included in the calculations, but their positions were shifted to a $\mathrm{C}-\mathrm{H}$ bond length of $1.08 \AA$, keeping the experimental angles. All attempts using experimental $\mathrm{H}$-atom positions led to poorer results.

To investigate the energy surface in the vicinity of the minimum, the lattice energy of each compound was computed as a function of the above-mentioned subrotations and mapped as the two-dimensional cross sections of the three-dimensional energy surface. If the proposed energy approach is valid, then the surface must have a minimum in the neighbourhood of the experimentally determined conformation. Subrotations of atom groups were carried out by means of the rotation matrix (International Tables for $X$-ray Crystallography, 1972):

$$
\left.R=\left[\begin{array}{ll}
\cos \alpha+L_{1}{ }^{2}(1-\cos \alpha) & L_{1} L_{2}\left(1-\cos \alpha+L_{3} \sin \alpha\right) \\
L_{1} L_{2}(1-\cos \alpha)-L_{3} \sin \alpha & \cos \alpha+L_{2}^{2}(1-\cos \alpha) \\
L_{3} L_{1}(1-\cos \alpha)+L_{2} \sin \alpha & L_{2} L_{3}(1-\cos \alpha)-L_{1} \sin \alpha \\
L_{3} L_{1}(1-\cos \alpha)-L_{2} \sin \alpha \\
L_{2} L_{3}(1-\cos \alpha)+L_{1} \sin \alpha \\
\cos \alpha+L_{3}^{2}(1-\cos \alpha)
\end{array}\right]\right)
$$

where $L_{1} L_{2} L_{3}$ are the Cartesian direction cosines of the rotation axis, which is taken coincident with the bond joining the subgroup to the molecule, and $\alpha$ is the angle of rotation about that axis, counterclockwise being positive. Calculations of energy were performed without considering Coulombic interactions.

\section{Results and discussion}

Results of energy minimization of the experimental structure are given in Table 2 , both without and with consideration of electrostatic interactions. The molecular position and orientation are expressed in terms of the displacement of the centre of mass $\left(\Delta \mathbf{r}_{m}\right)$ and the magnitude of the molecular rotation $(\Delta \theta)$, which is given by the rotation matrix referred to the inertia axes of the molecule. The increments on each of the subrotation $\left(\Delta \tau_{i}\right)$ and the cell parameters obtained at the end of the process are given as well. Also a factor is included, formulated as:

$$
R=\sum\left\{\left[X_{e}\right]-\left[X_{t}\right]\right\} / \sum\left[X_{e}\right]
$$

which expresses the agreement between the experimental coordinates $\left(X_{e}\right)$ and the theoretical coordinates calculated by the minimization process $\left(X_{t}\right)$.
Table 2. Results of energy minimization

$\begin{array}{ccccccc} & & (\mathrm{I}) & (\mathrm{II}) & (\mathrm{III}) & (\mathrm{IV}) & (\mathrm{V}) \\ \text { Translation, } & (a) & 0.15 & 0.13 & 0.49 & 0.03 & 0.00 \\ \left|\Delta \mathbf{r}_{\boldsymbol{m}}\right|(\AA) & (b) & 0.16 & 0.16 & 0.40 & 0.00 & 0.00 \\ \begin{array}{c}\text { Rotation, } \\ |\Delta \theta|\left(^{\circ}\right)\end{array} & (\text { a) } & 3.4 & 3.9 & 2.9 & 2.2 & 1.7 \\ \text { Subrotations } & & 2.9 & 3.1 & 2.3 & 0.0 & 2.1 \\ \left|\Delta \tau_{1}\right|\left(^{\circ}\right) & (a) & 4.5 & 1.6 & 2.2 & 0.5 & 0.1 \\ \left|\Delta \tau_{2}\right|\left(^{\circ}\right) & & 3.4 & 20.9 & 2.9 & 0.5 & 0.3 \\ \left|\Delta \tau_{3}\right|\left(^{\circ}\right) & & 31.4 & 18.2 & 5.6 & 0.3 & 0.0 \\ & (b) & 3.3 & 2.8 & 0.7 & 0.1 & 0.0 \\ & & 0.0 & 23.9 & 1.9 & 0.0 & 0.1 \\ & & 31.1 & 20.2 & 3.8 & 0.0 & 0.0\end{array}$

Cell parameters

Observed

$\begin{array}{llllll}a(\AA) & 13.189(4) & 13.718(1) & 7.440(1) & 10.236(1) & 13.247(1)\end{array}$

$\begin{array}{llllll}b(\AA) & 8.636(2) & 11.090(1) & 14.545(1) & 9.789(1) & 20.335(3)\end{array}$

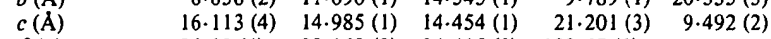

$\beta\left({ }^{\circ}\right) \quad 94.19(4) \quad 98.162(2) \quad 94.415(3) \quad 102.67(1)$

Calculated

$a(\AA)$

$b(\AA)$

(a) $13 \cdot 111$

13.614

$7 \cdot 226$

$8.526 \quad 10.982$

$16.039 \quad 14.918$

$14 \cdot 279$

14.203

$10.247 \quad 13.249$

$\beta\left({ }^{\circ}\right)$

(b)

$98.69 \quad 96.07$

$\begin{array}{llll}13.544 & 7.169 & 10.237 & 13.248\end{array}$

$\begin{array}{llll}11.004 & 14.153 & 9.789 & 20.336\end{array}$

$\begin{array}{lllll}16.031 & 14.936 & 14.225 & 21.200 & 9.491\end{array}$

(a) 0.05

97.72

103.54

$R$

Notes: (a) Coulombic interactions were not considered, (b) Coulombic interactions were considered.

All translational shifts are under $0 \cdot 2 \AA$ except those of compound (III), which are larger $(0.49$ and $0.40 \AA$ respectively); rotational angles are small, with a maximum value of $4^{\circ}$ in compound (II). Subrotations fit well; only $\left[\Delta \tau_{3}\right]$ of compound (I) is about $30^{\circ}$ and $\left[\Delta \tau_{2}\right]$ and $\left[\Delta \tau_{3}\right]$ of compound (II) are about $20^{\circ}$. Cell parameters are reproduced with better than $4 \%$ accuracy and disagreement between observed and calculated coordinates is under $6 \%$ in all cases.

In view of the results obtained, and since the largest deviations correspond to subrotations, all calculations were repeated with parameters fixed (i.e., energy was minimized with respect to translation, rotation and cell constants). However, these conditions led to a worse fit of the calculated structure to the experimental one, including those cases where subrotations did not present such a large deviation, as in compound (III). In particular, translation and cell parameters exhibit notably larger increments, the last reaching a shift of $13 \%$.

Since temperature effects and lattice vibrations were not taken into account, the energy minimization led, as expected, to decreases of cell volumes in all cases except compound $(\mathrm{V})$, where variations are insignificant.

As can be deduced from Table 2, the influence of the Coulombic interactions on the optimized parameters is not very clear. While some parameters are slightly improved, others present larger shifts when electrostatic energy is included in the calculation. In general, agreement is similar in both cases, but there is a trend to 
a better fit with consideration of Coulombic contributions, particularly in compound (IV). The results are, however, good enough without considering electrostatic energy to justify its omission, especially as its evaluation increases notably the computation time required.

The more satisfactory results obtained for compounds (IV) and (V) than for compounds (I), (II) and (III) may depend on the fact that heavy atoms are more screened in (IV) and (V), which could be attributed to the high branching of the $\mathrm{SiMe}_{3}$ ligands in compound (IV), or to the large coordination around the Ta atom in compound (V).

Fig. 1 shows the two-dimensional cross sections of the energy surface of each compound, in the three main projections. Contours are calculated with an accuracy of $5^{\circ}$ for the angles $\tau_{1}, \tau_{2}$ and $\tau_{3}$ varying within the range $\pm 15^{\circ}$ from the point corresponding to the experimentally observed conformations [point $(0,0,0)$ in
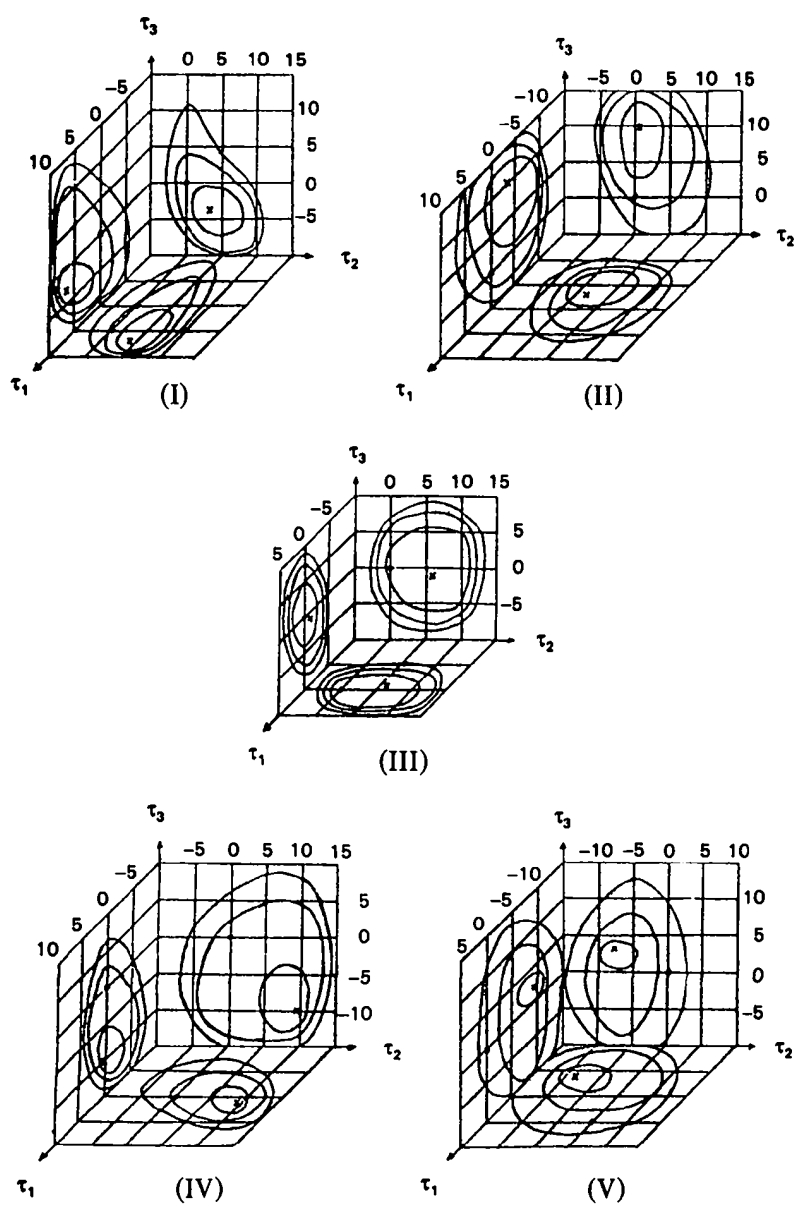

Fig. 1. Cross-section $U\left(\tau_{1}, \tau_{2}, \tau_{3}\right)$, through the energy surface minimum point, for compounds (I), (II), (III), (IV) and (V). the maps]. Near the minimum, calculations have been performed with an accuracy of $1^{\circ}$. The minimum position on each section is designated by a cross. Calculations of the energy surface as a function of the three subrotations led to minima at points $(7,4,-3)$, $(-3,1,10),(-1,7,-2),(-1,9,-10)$ and $(-8,-8,3)$ for $\tau_{1} \tau_{2} \tau_{3}$.angles of compounds (I), (II), (III), (IV) and (V) respectively.

In summary, lattice-energy calculations as a function of torsion angle lead to satisfactory results, as energy minimization does, when the energy is evaluated in the atom-atom model. This unexpected fact, in view of the roughly approximated potential functions used, could be explained in terms of the heavy atoms being screened. In fact, packing energy due to the metal atom is about $20 \%$ of the total energy in compounds (I), (II) and (III) and less than $10 \%$ in compounds (IV) and (V). Although additional work is needed, the results given in this paper suggest that the atom-atom approach may be used for organometallic compounds when limited accuracy is needed.

We thank Professor M. Martinez-Ripoll for assistance in programming and Professor J. Fayos for valuable discussions.

\section{References}

Antiñolo, A., Otero, A., Urbanos, F., Garcia-Blanco, S., MARTÍNEZ-CARRERA, S. \& SANZ-APARICIO, J. (1988). J. Organomet. Chem. In the press.

Estrada, M. D., Conde, A. \& Márquez, R. (1983). Acta Cryst. B39, 739-742.

Fandos, R., Gómez, M., Royo, P., García-Blanco, S., MARTínez-CARrera, S. \& SANZ-Aparicio, J. (1987). Organometallics, 6, 1581-1583.

Giglio, D., Liquori, A. M. \& Mazzarella, L. (1969). Lett. Nuovo Cimento, 1, 135-139.

Govers, H. A. J. (1975). Acta Cryst. A31, 380-385.

International Tables for X-ray Crystallography (1972). Vol. II, p. 62. Birmingham: Kynoch Press. (Present distributor D. Reidel, Dordrecht.)

KitAigorodsky, A. I. (1973). Molecular Crystals and Molecules. New York, London: Academic Press.

Mason, E. A. \& Kreevoy, M. M. (1955). J. Am. Chem. Soc. 77, 5808-5814.

Mason, E. A. \& Rice, W. E. (1954a). J. Chem. Phys. 22, 843-851.

Mason, E. A. \& Rice, W. E. (1954b). J. Chem. Phys. 22, 522-534.

MirSKY, K. (1976). Acta Cryst. A32, 199-207.

Rinaldi, R. P. \& Pawley, G. S. (1973). Nuovo Cimento B, 16, $55-62$.

Sanz-Aparicio, J., Martínez-Carrera, S. \& García-Blanco, S. (1986a). Acta Cryst. C42, 1121-1123.

Sanz-Aparicio, J., Martínez-Carrera, S. \& García-Blanco, S. (1986b). Z. Kristallogr. 175, 195-202.

Sanz-Aparicio, J., Martínez-Carrera, S. \& García-Blanco, S. (1987). Acta Cryst. C43, 2009-2011.

SKoRCZYK, R. (1976). Acta Cryst. A32, 447-452.

Villares, P., Jiménez-Garay, R., Conde, A. \& Márquez, R. (1976). Acta Cryst. B32, 2293-2296.

Williams, D. E. (1972). Acta Cryst. A28, 629-635. 